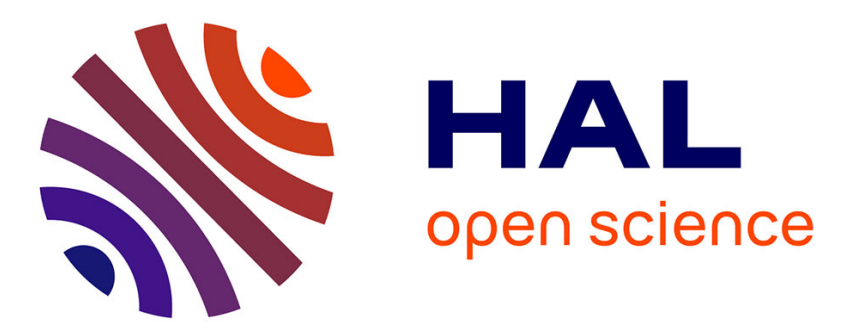

\title{
Exploring Interface Sign Ontologies for Web User Interface Design and Evaluation: A User Study
}

\author{
Muhammad Nazrul Islam
}

\section{To cite this version:}

Muhammad Nazrul Islam. Exploring Interface Sign Ontologies for Web User Interface Design and Evaluation: A User Study. 15th International Conference on Informatics and Semiotics in Organisations (ICISO), May 2014, Shanghai, China. pp.87-96, 10.1007/978-3-642-55355-4_9 . hal-01350913

\section{HAL Id: hal-01350913 \\ https://inria.hal.science/hal-01350913}

Submitted on 2 Aug 2016

HAL is a multi-disciplinary open access archive for the deposit and dissemination of scientific research documents, whether they are published or not. The documents may come from teaching and research institutions in France or abroad, or from public or private research centers.
L'archive ouverte pluridisciplinaire HAL, est destinée au dépôt et à la diffusion de documents scientifiques de niveau recherche, publiés ou non, émanant des établissements d'enseignement et de recherche français ou étrangers, des laboratoires publics ou privés. 


\title{
Exploring Interface Sign Ontologies for Web User Interface Design and Evaluation: A User Study
}

\author{
Muhammad Nazrul Islam \\ Turku Centre for Computer Science (TUCS), \\ Department of Information Technologies, \\ Åbo Akademi University, \\ Turku - 20520, Finland \\ nislam@abo.fi; nazrulturku@gmail.com
}

\begin{abstract}
The aim of this paper is twofold: firstly, to find the set of ontologies (i.e., the set of concepts and skills) presupposed by users when interpreting the meaning of web interface signs (i.e., the smallest elements of web user interfaces), and secondly, to investigate users' difficulties in interpreting the meanings of interface signs belonging to different kinds of ontologies. In order to achieve these aims an empirical user study was conducted with 26 test participants. The study data was gathered by semi-structured interviews and questionnaires. Following an empirical research approach, descriptive statistics and qualitative data analysis were used to analyze the data. The study results provide a total of twelve ontologies and reveal the users' difficulties in interpreting the meanings of interface signs belonging to different kinds of ontologies.
\end{abstract}

Keywords: Web user interface, Ontology, Semiotics, Interface sign, Web usability, User interface design.

\section{Introduction}

\subsection{Web Interface Sign and Ontology}

The web user interface (UI) is the 'window to the world' through which interactions between end users and web applications are mediated, organizations communicate with customers, and the like [1]. A web UI encompasses a number of navigational links, symbols, command buttons, thumbnails, icons, small images, etc. These smallest elements are defined in this paper as interface signs (see Fig. 1, example interface signs are marked by ovals). Interface signs are treated as one of the most crucial elements of web UIs. The main reasons are [2-4]: (a) the content and functions of web applications are essentially directed by interface signs, and (b) users interact with web applications by means of interface signs, (c) an interface sign is designed by designer(s) as an encoded form and users should properly decode or interpret the sign to get the meaning of this sign, and (d) inaccurate interpretation of interface signs leads users to usability problems and to low task performance. Designing user 
intuitive interface signs is essential to ensure effective and efficient system use, to maintain the user satisfied, to achieve system's learnability, to provide users the means to communicate, etc. i.e., to improve the usability of web applications [3], [5], [6-7]. Interface sign design principles are semiotics by nature as semiotics is considered as the doctrine or science of signs [8-10]. Semiotics can be defined as "the study of signs, signification, and signifying systems" [11].

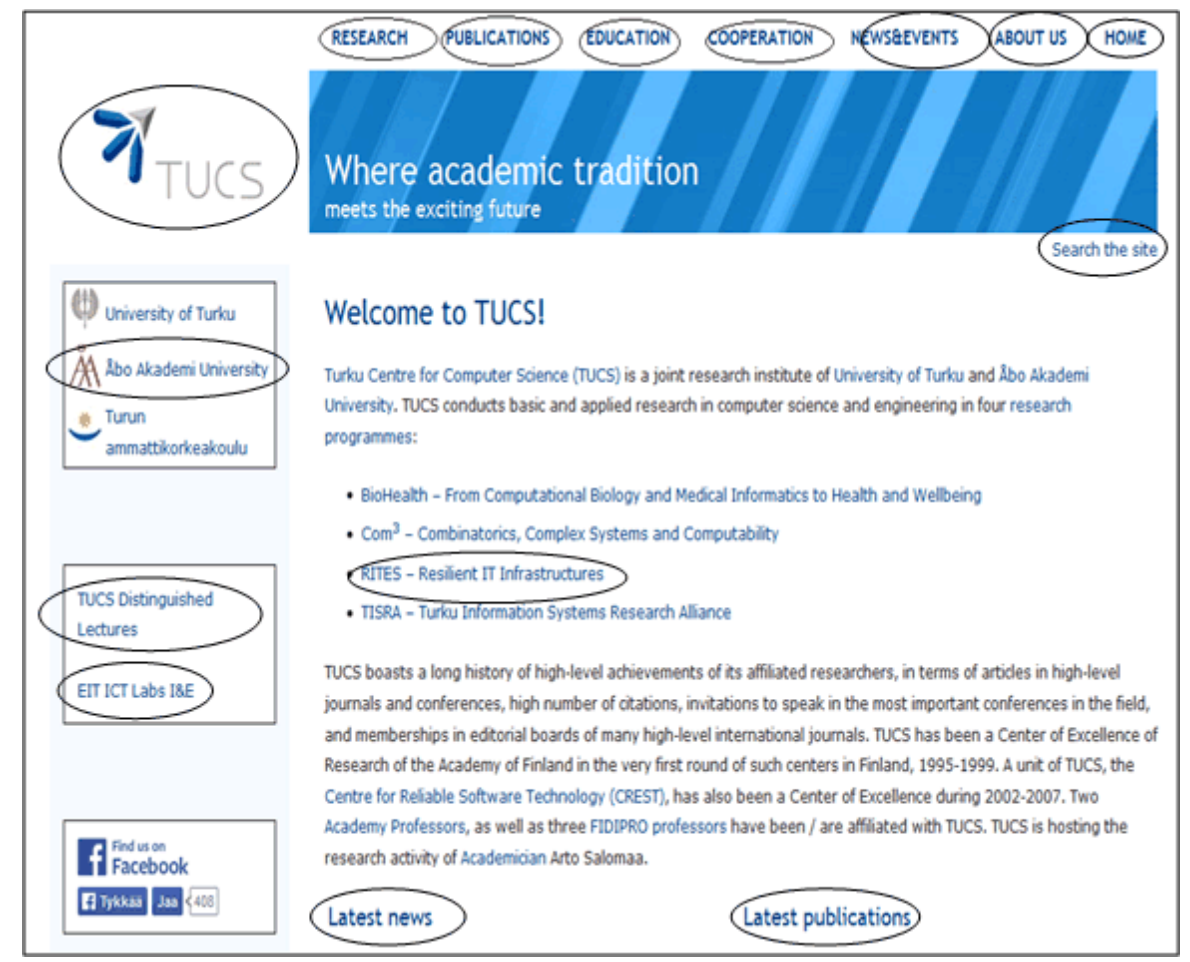

Fig. 1. Example interface signs marked by ovals; snapshot of Turku Centre for Computer Science retrieved from www.tucs.fi on January 2014

The term 'ontology' is defined as the set of concepts and skills that a user should know for understanding the referential meaning of an interface sign [2] [12]. From the user's perspective, ontology refers to the knowledge or concepts that are needed to understand and properly interpret the meaning of an interface sign. From the designers' perspective, ontology refers to the knowledge or concepts presupposed and referred to by an interface sign. For example, an interface sign 'Inbox' in an email application may be well designed in terms of color, layout, position, etc. but will not make any sense to the users who do not know what the concept of 'Inbox' refers to. Here, this 'concept' is defined as 'ontology'. The concept and definition of ontology provided by Speroni [12] and Bolchini et al. [2] are considered as background theory of this paper. According to Speroni [12], the most common ontologies used in 
information intensive websites are: Internet Ontology (knowledge related to the internet use), InterLocutor/Institution Ontology (knowledge related to the owner of the website), Commonsense Ontology (knowledge belonging to the user's background, and referring to common and everyday terms), Website Ontology (knowledge related to a particular website), Web Domain Ontology (knowledge related to a specific web domain), Context Ontology (knowledge related to a specific context of interface sign), and Topic Ontology (knowledge related to a specific topic or subject of a website).

\subsection{Motivation and Study Questions}

Ontologies are important for interface sign design and evaluation for the following reasons [2] [12] [13-15]:

i) Users hold a set of ontologies to interpret the meaning of interface signs. In other words, users interpret the meaning of interface signs based on their presupposed knowledge.

ii) A proper matching between the ontology or ontologies referred to by an interface sign and the ones known by a user helps the user to properly interpret the meaning of this sign.

iii) UI practitioners should know the users of a system in order to design or evaluate it (i.e., 'knowing the users'). In other words, practitioners need to know what kind of presupposed knowledge (i.e., ontologies) is used by the end-users when interpreting the meaning of interface signs.

iv) Practitioners can model the profiles of end-users based on their familiarity with different kinds of ontologies. This model assists practitioners to create a design or evaluation paradigm for web user interface design and evaluation.

However, the set of ontologies provided by Speroni [12] and Bolchini et al. [2] was an example list of most common ontologies used in information intensive web UI. In their work, they have also stated that the set of ontologies can be different depending on different websites. A few studies were conducted to observe users difficulties in interpreting the meaning interface signs belonging to different kinds of ontologies [13-15]. These studies were conducted mainly using an expert inspection as a method, considered the ontologies proposed by Speroni [12], and focused only on information intensive websites.

Therefore, the objectives of this paper were to find the set of ontologies presupposed by users when interpreting the meaning of web interface signs, and to investigate users' difficulties in interpreting the meanings of interface signs belonging to different kinds of ontologies. The fundamental question was: what ontologies are used to interpret the meaning of web interface signs? In order to achieve these objectives, an empirical study was conducted with a total of 26 test participants. The study results provide a set of twelve ontologies, a few features related to ontology mapping in interpreting the meaning of the interface signs, and reveal the participants' difficulties in interpreting the meaning of interface sign belonging to different kinds of ontologies. It is important to mention here that an earlier version of this paper is published in [16]. 
The paper proceeds as follows. Section 2 presents the study method. The study results are discussed in section 3. The discussion and ideas for future work are presented in the final section.

\section{Study Method}

The study followed an empirical research approach. The study data was collected by semi-structured interviews and questionnaires. The empirical study was designed and conducted primarily to find the determinants (themes) and the attributes (sub-themes) of user-intuitive interface signs. However, the scope of this paper was limited to a specific objective, which was a part of the primary objective of the aforementioned study, - i.e., to explore the web interface sign ontologies for interface sign design and evaluation. Thus this paper focused only on users' presupposed knowledge or ontologies (a determinant of user-intuitive interface signs), and considered data related to web sign ontologies. The study data was analysed by descriptive analysis and qualitative data analysis. The profiles of test participants and study procedure are discussed briefly here. The methodology is discussed more comprehensively in [17].

Participants: A total of 6 female and 20 male participants (i.e., a total of 26 participants) were recruited to conduct this study. Participants were aged 22-41 [M $(\mathrm{SD})=25.85(4.86)] .5$ participants were company employees, 1 research personal, and remaining 20 were graduate students at Åbo Akademi University (AAU), Finland. Company employees were also studying as graduate students at ÅA. Each participant had good experience in accessing university websites and using email applications. 5 participants had experience in accessing museum websites, and 17 participants had prior experience with use of online calendars. Each participant had experience with (real-world) calendars and visited a few (real-world) museums.

Study procedure: The study was conducted in a usability test laboratory in Finland. A total of 72 interface signs were selected from user interfaces of two web application domains (online calendar and email) and two web domains (university and museum websites). Three types of questions: open ended, probing, and closed questions were developed following the interview guidelines suggested by Stanton \& Young [18].

Each test was conducted one by one. The following activities were followed in each test session with each participant. Firstly test subjects filled up pre-test questionnaires and signed a test-consent form; secondly a short lecture was given to inform the test subjects about the test in general: test procedure, test participants' roles, etc.; and finally test subjects were asked to answer a set of questions for each interface sign presented to them. Selected interface signs were presented to test subjects in two arrangements: sign without context and sign with context. Test subjects were not allowed to click on the signs; they were only supposed to respond to a number of questions for each interface sign such as: What could be the referential meaning of this sign? Why do you think this (user's response for the first question) is the meaning of this sign? How certain or confident are you that you are correct in your interpretation (score: 1(very low) - 7(very high))? What complications or difficulty do you feel to interpret this sign (score: 1(very easy) - 7(extremely difficult))? Each test-session generally took about 100-120 minutes for each 
participant. Each test session was audio-video recorded. Both qualitative and quantitative data were collected and analyzed.

\section{$3 \quad$ Study Results}

The study provides the following results:

- A set of twelve interface sign ontologies.

- A few features of ontology mapping in interpreting the meaning of the interface signs.

- Reveal the participants' difficulties in interpreting the meaning of interface signs belonging to different kinds of ontologies.

Next we will discuss each study results more comprehensively.

\subsection{Set of Ontologies}

The study found a total set of twelve ontologies to interpret the meaning of the interface signs. A few of them (i.e., number $i$, vi-viii, $x$, and xii), as discussed in section 1.1, are also proposed by Speroni and Bolchini et al. in (Bolchini et al. 2009; Speroni 2006). The set of ontologies, their definition and examples are briefly presented in table 1 .

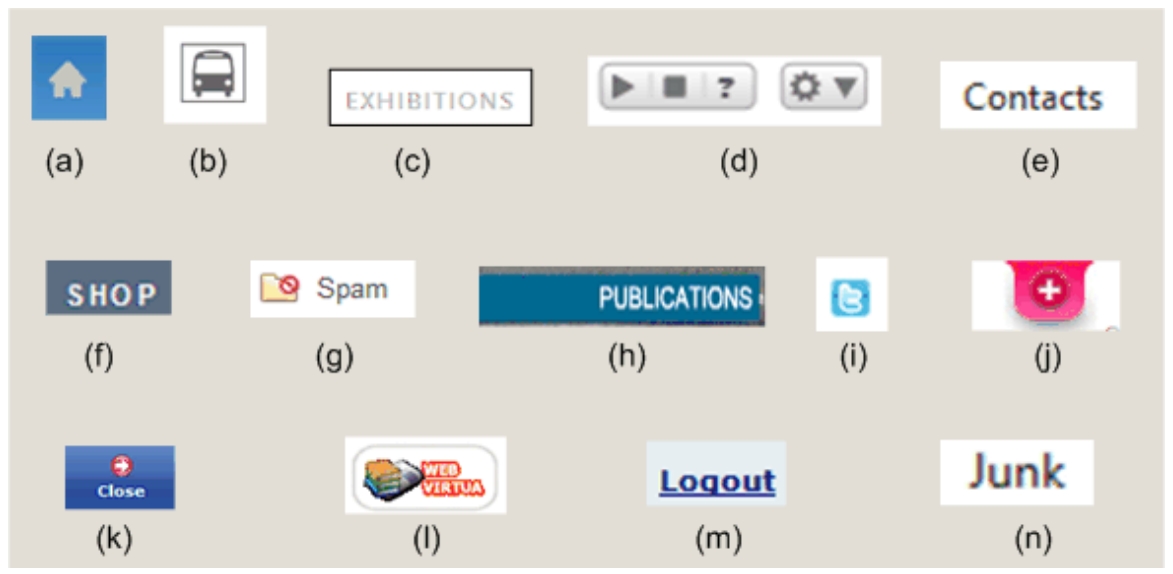

Fig. 2. A set of interface signs 
Table 1. Set of interface sign ontologies

\begin{tabular}{|c|c|c|}
\hline \# & & Ontologies \\
\hline \multirow[t]{3}{*}{$i$} & Ontology & Internet Ontology \\
\hline & Definition & $\begin{array}{l}\text { The knowledge of world of web, web browsing and its concepts and } \\
\text { conventions. }\end{array}$ \\
\hline & Example & $\begin{array}{l}\text { A number of participants interpreted the }<\text { Home }>\text { (see Fig. } 2 . \text { a) sign } \\
\text { correctly because they were familiar with the world of web and } \\
\text { internet browsing. One responded "...It is for home page...my } \\
\text { experience of browsing on internet; it is a home icon for web } \\
\text { entrance...." }\end{array}$ \\
\hline \multirow[t]{3}{*}{$i i$} & Ontology & Real World Ontology \\
\hline & Definition & The knowledge of the real world experiences and concepts. \\
\hline & Example & $\begin{array}{l}\text { One participant interpreted the <Bus> (see Fig. 2.b) sign correctly } \\
\text { because he was familiar with it. He responded "....There is a clear } \\
\text { picture of the bus. I see this at the bus stop....." }\end{array}$ \\
\hline \multirow[t]{3}{*}{ iii } & Ontology & System Ontology \\
\hline & Definition & The knowledge of the (studied) system, its functionalities \& concepts. \\
\hline & Example & $\begin{array}{l}\text { One participant interpreted the 'Exhibition' (see Fig. 2.c) sign } \\
\text { correctly because he had experience with museum though he never } \\
\text { visited museum website. He responded ".... The term is known to me. } \\
\text { It is a general term. I have heard this term in the museum....." }\end{array}$ \\
\hline \multirow[t]{3}{*}{$i v$} & Ontology & Computer Ontology \\
\hline & Definition & The knowledge of computers and computer uses. \\
\hline & Example & $\begin{array}{l}\text { One participant interpreted the <media player> (see Fig. 2.d) sign } \\
\text { correctly because he had used the Windows Media Player in his } \\
\text { computer. He responded "...I am familiar with these sign from the } \\
\text { Windows Media Player...." }\end{array}$ \\
\hline \multirow[t]{3}{*}{$v$} & Ontology & Mobile Ontology \\
\hline & Definition & The knowledge of mobile and mobile application uses. \\
\hline & Example & $\begin{array}{l}\text { A number of participants interpreted the 'Contact' (see Fig. } 2 . \text { e) sign } \\
\text { correctly because they were very familiar with the use of mobile } \\
\text { phone. One responded "...I am familiar with this sign...like in my } \\
\text { phone I have contacts....." }\end{array}$ \\
\hline \multirow[t]{3}{*}{$v i$} & Ontology & Common-Sense Ontology \\
\hline & Definition & $\begin{array}{l}\text { The knowledge belonging to a common background of users and that } \\
\text { uses common sense. }\end{array}$ \\
\hline & Example & $\begin{array}{l}\text { A number of participants interpreted the 'Shop' (see Fig. 2.f) sign } \\
\text { correctly based on their background knowledge. One responded } \\
\text { ".... There is a clear picture of the bus. I see this at the bus stop....." }\end{array}$ \\
\hline \multirow[t]{3}{*}{$v i i$} & Ontology & Topic Ontology \\
\hline & Definition & The knowledge of a particular subject or topic the website talks about. \\
\hline & Example & $\begin{array}{l}\text { Two participants interpreted the <Bus> (see Fig. 2.b) sign in a } \\
\text { museum website inaccurately because they thought that the icon } \\
\text { stands for a specific exhibition related to vehicles. One responded } \\
\text { "....It is kind of bus exhibition....." The sign actually stands for } \\
\text { providing information on how to reach the museum. }\end{array}$ \\
\hline
\end{tabular}


Table 1. Set of interface sign ontologies (Continued...)

\begin{tabular}{|c|c|c|}
\hline$\#$ & & Ontologies \\
\hline \multirow[t]{3}{*}{ viii } & Ontology & Current Web Domain Ontology \\
\hline & Definition & $\begin{array}{l}\text { The knowledge of web interface signs which are specific enough to } \\
\text { the current web domain (e.g., email application domain). }\end{array}$ \\
\hline & Example & $\begin{array}{l}\text { A number of participants interpreted the }<\text { Spam }>\text { (see Fig. } 2 . g \text { ) sign in } \\
\text { an email application correctly because of their familiarity with the } \\
\text { email application. One responded "...I know this meaning because of } \\
\text { my previous knowledge of using email applications...." }\end{array}$ \\
\hline \multirow[t]{3}{*}{$i x$} & Ontology & Other Web Domain Ontology \\
\hline & Definition & $\begin{array}{l}\text { The knowledge of web interface signs which are specific enough to a } \\
\text { particular web domain other than the web domain where the sign is } \\
\text { currently available. }\end{array}$ \\
\hline & Example & $\begin{array}{l}\text { One participant interpreted the 'Publications' (see Fig. } 2 . \mathrm{h} \text { ) sign in a } \\
\text { museum website correctly because of his familiarity with university } \\
\text { websites (i.e., educational web domain). He responded "....From } \\
\text { university domain, I know what is a publication. I never had seen } \\
\text { 'Publications' in a museum website..." }\end{array}$ \\
\hline \multirow[t]{3}{*}{$x$} & Ontology & Organization Ontology \\
\hline & Definition & $\begin{array}{l}\text { The knowledge of web interface signs that refer to the institution or } \\
\text { organization that owns a website or an application. }\end{array}$ \\
\hline & Example & $\begin{array}{l}\text { A number of participants interpreted the <Twitter }>\text { (see Fig. } 2 . \mathrm{i} \text { ) sign } \\
\text { correctly because they were familiar with Twitter. One responded } \\
\text { "...I never use Twitter. But I know what Twitter is ....." }\end{array}$ \\
\hline \multirow[t]{3}{*}{$x i$} & Ontology & Cultural Ontology \\
\hline & & $\begin{array}{l}\text { The knowledge of web interface signs which are specific to a } \\
\text { particular cultural context. }\end{array}$ \\
\hline & Example & $\begin{array}{l}\text { One participant interpreted the <red color plus> (see Fig. } 2 . j \text { ) sign in a } \\
\text { museum website as 'the museum's hospital or medical help center } \\
\text { information', because this kind of sign (i.e., red color plus sign) } \\
\text { represents hospital or medical help in her country of origin. }\end{array}$ \\
\hline \multirow[t]{3}{*}{$x i i$} & Ontology & Website Ontology \\
\hline & Definition & $\begin{array}{l}\text { The knowledge of web interface signs which are specific to a } \\
\text { particular website. }\end{array}$ \\
\hline & Example & $\begin{array}{l}\text { A number of participants were unable to interpret the }\langle\text { Close }\rangle \text { sign } \\
\text { (see Fig. 2.k) sign in an email application because they never visited } \\
\text { this website and also were not familiar with the sign. One responded } \\
\text { "....I think it is something different because if it is for close then it } \\
\text { should be X, but it has an arrow. So, may be it is for proceed. I never } \\
\text { use this sign with arrow icon. However, it may mean closing a tab or } \\
\text { email..." This sign was actually designed for logging-out. }\end{array}$ \\
\hline
\end{tabular}

\subsection{Ontology Mapping}

The following features, related to ontology mapping in interpreting the meaning of interface signs, were also found in the study. 
(i) The set of ontologies found in this study includes both the designers' perspectives in interface signs design and the users' perspectives in interface signs interpretation. In other words, ontology derived from the users' perspective implies that it is referred to by the interface signs. For example, when a participant interpreted the 'Junk' sign (see Fig. 2.n) in an email application because of his familiarity with Current Web Domain Ontology, it shows that Current Web Domain Ontology is referred to by the 'Junk' sign from the designers' perspective.

(ii) Participants used single or multiple ontologies to interpret the meaning of the interface sign. Similarly, an interface sign may belong to a single ontology or to multiple ontologies. However, a proper matching between ontology/ontologies referred to by an interface sign and the one(s) owned by the participants led them to interpret the interface signs correctly. For example, the <Spam $>$ (see Fig. 2.g) sign in an email application pointed to the Current Web Domain Ontology. Participants familiar with the email application domain interpreted the meaning of this sign accurately. Again, the 'Contact' (see Fig. 2.e) sign in an email application built on multiple ontologies such as Mobile Ontology, Current Web Domain Ontology, Internet Ontology, Other Web Domain Ontology, and Common-Sense Ontology. A number of participants interpreted the meaning of this sign accurately because of their familiarity with these ontologies.

(iii) When multiple ontologies are referred to by an interface sign, then participants interpreted the sign meaning only for ontology/ontologies with which they were familiar (i.e., a familiar ontology supports an unfamiliar ontology to get the sign meaning). For example, the <Web Virtua> sign (see Fig. 2.1) in a university website assumed the Current Web Domain Ontology, Cultural Ontology, Internet Ontology, and Website Ontology. A few participants interpreted the meaning of this sign properly because of their familiarity with Current Web Domain Ontology (the appended images refer to the university library in a university website) and Internet Ontology (the term 'web' is familiar from internet access).

(iv) An ontology conflict [12] occurred when participants were confused with which ontology/ontologies to consider in interpreting the meaning of an interface sign. Ontology conflict increased perceived interpretation difficulty as well as decreased meaning interpretations' accuracy. For example, the 'Close' (see Fig. 2.k) sign in an email application built on the Website Ontology, because the 'Close' sign was specific to this application for signing-out. A number of participants' treated this sign as built on Computer Ontology, Common-Sense Ontology, Internet Ontology, or Mobile Ontology to close an open or pop-up window. Thus, an ontology conflict occurred.

\subsection{Difficulties related to Different Kinds of Ontologies}

This study also investigated the participants' difficulties in interpreting the meanings of interface signs belonging to different kinds of ontologies. The study found that difficulty experienced to interpret an interface sign by an individual depends on his or her familiarity with the ontology / ontologies assumed for the interface sign. For 
example, a participant familiar with Current Web Domain Ontology led him/her to interpret the meaning of interface signs that belong to the Current Web Domain Ontology with comparatively low perceived difficulty. However, because participants had heterogeneous profiles (i.e., they had different levels of familiarity with each kind of ontology), the study also found that participants experienced (a) lower level of perceived meaning interpretation difficulty with interface signs that belong to Internet Ontology, Computer Ontology, Mobile Ontology, Current Web Domain Ontology, and Common-Sense Ontology; (b) average level of perceived meaning interpretation difficulty with interface signs that belong to Other Web Domain Ontology, System Ontology, Real World Ontology, Cultural Ontology, Organizational Ontology, and Topic Ontology; and (c) higher level of perceived meaning interpretation difficulty with interface signs that belong to Website Ontology. For example, both 'logout' (see Fig. 2.m) and 'Close' (see Fig. 2.k) signs stand for logging-out from email applications. Participants experienced less perceived difficulty to interpret the meaning of 'Logout' sign and high perceived difficulty to interpret the meaning of the 'Close' sign because these signs belong to Internet Ontology and Website Ontology respectively and participants' familiarity level with these ontologies was high and less respectively.

\section{Discussion and Conclusions}

This paper explores ontologies of web interface signs for designing and evaluating web interfaces. The study results provided a set of ontologies to interpret the meaning of interface signs, and a set of features of ontology mapping in interpreting the meaning of interface signs, and also showed users' difficulty in interpreting the meaning of interface sign.

The results will help practitioners at least in the following two ways: Firstly, the results will assist practitioners to model the users' profiles based on their familiarity with ontologies, which in turn assist them to design and evaluate interface signs. Secondly, the results will provide the following set of ontological guidelines for interface sign design and evaluation:

(i) design interface signs based on users' familiarity level with ontologies;

(ii) design interface signs that belong to multiple ontologies;

(iii) avoid ontology conflict when creating interface signs;

(iv) (re)design interface signs which belong to ontologies, with which user experienced lower level of perceived difficulty (e.g., Internet Ontology); and

(v) avoid to create interface signs that belong only to the 'Website Ontology'.

For researchers, a number of ways of fruitful research still remain such as conducting similar studies on mobile interfaces, conducting action research to validate the study outcomes, and the like. However, the author intends to conduct future work to validate the study results and alleviate the subjectivity of ontologies in web UI design and evaluation process to improve system usability.

Acknowledgements. The author would like to thank all the participants of this study. Finnish Economic Education Foundation and Nokia Foundation provided the grant that has made this research possible. For this, they are gratefully acknowledged. 


\section{References}

1. Benbasat, I.: Human-Computer Interaction for Electronic Commerce: A Program of Studies to Improve the Communication between Customers and Online Stores. In: D. Galletta, and P. Zing (eds.): Human-Computer Interaction and Management Information Systems: Application, Armonk, NY (2006) 17-28

2. Bolchini, D., Chatterji, R., Speroni, M.: Developing heuristics for the semiotics inspection of websites. In: Proceedings of the 27th ACM international conference on Design of Communication, ACM Press, USA (2009) 67-71

3. De Souze, C.S.: The Semiotic Engineering of Human-Computer Interaction, Cambridge: MIT Press, Cambridge (2005)

4. Islam, M.N.: Exploring the Impact of Interface Signs' Interpretation Accuracy, Design, and Evaluation on Web Usability: A Semiotics Perspective. Journal of Systems and Information Technology (2014)

5. de Souza, C. S., Leitão, C. F., Prates, R. O., da Silva, E. J.: The Semiotic Inspection Method. In: Proceedings of the VII Brazilian symposium on Human Factors in Computing Systems, ACM Press (2006) 148-157.

6. Islam, M. N.: A Systematic Literature Review of Semiotics Perception in User Interfaces," Journal of Systems and Information Technology (2013), pp. 45-77.

7. Islam, M.N., and Tétard, F.: Integrating Semiotics Perception in Usability Testing to Improve Usability Evaluation. In: M.A.G. Ruiz (eds.): Cases on Usability Engineering: Design and Development of Digital Products, IGI Global, USA (2013) 144-168.

8. Peirce, C.S. : Collected Writings (8 Vols.), (Ed. Charles Hartshorne, Paul Weiss \& Arthur Burks), Cambridge, MA: Harvard University Press (1931-58).

9. Andersen, P.: Computer Semiotics. Scandinavian J. of Information Systems (1992) 3-30.

10. Saussure, F.D. 1983. Course in General Linguistics (trans. Harris, R.), Duckworth, London.

11. Stam, R., Burgoyne, R. and Lewis, S.F.: New Vocabularies in Film Semiotics: Structuralism, Post-Structuralism and Beyond, Taylor \& Francis, London (1992).

12. Speroni, M.: Mastering the Semiotics of Information-Intensive Web Interfaces, Unpublished doctoral dissertation, University of Lugano, Switzerland (2006).

13. Islam, M. N.: Semiotics Perception towards Designing Users' Intuitive Web User Interface: A Study on Web Sign Redesign. In: Rahman et al. (eds.): Knowledge and Technologies in Innovative Information Systems, LNBIP 129, Springer-Verlag (2012) 139-155.

14. Islam, M. N., Ali, M., Al-Mamun, A., and Islam, M.: Semiotics Explorations on Designing the Information Intensive Web Interfaces. International Arab Journal of Information Technology (2010) 45-54.

15. Islam, M. N.: Towards Designing Users' Intuitive Web Interface. In: Proceedings of the 6th International Conference on Complex, Intelligent, and Software Intensive Systems, IEE CS, Sicilia, Italy (2012) 513-518

16. Islam, M.N.: Towards Exploring Web Interface Sign Ontology: A User Study. In: proceeding of the 15th HCII International 2013, CCIS-373, Springer- Verlag (2013) 4145

17. Islam, M. N.: Towards Determinants of User-Intuitive Web Interface Signs. In: Marcus A.(eds.): Design, User Experience, and Usability. Design Philosophy, Methods, and Tools., Springer (2013) 84-93

18. Stanton, N.S., and Young, M.S. 1999. Guide to Methodology in Ergonomics: Designing for Human Use, UK: Taylor and Francis, UK (1999). 